OPEN ACCESS

Edited by:

Renato Cutrera,

Bambino Gesù Ospedale Pediatrico (IRCCS), Italy

Reviewed by: Andrew Bush,

Imperial College London,

United Kingdom

Yusei Ohshima,

University of Fukui, Japan

Francesca Santamaria, Università degli Studi di Napoli

Federico II, Italy

*Correspondence:

Gian L. Marseglia

gl.marseglia@smatteo.pv.it

Specialty section:

This article was submitted to

Pediatric Pulmonology,

a section of the journal

Frontiers in Pediatrics

Received: 21 April 2018 Accepted: 24 May 2018

Published: 19 June 2018

Citation: Licari A, Brambilla I, Marseglia A

De Filippo M, Paganelli V and Marseglia GL (2018) Difficult vs. Severe Asthma: Definition and Limits of Asthma Control in the Pediatric Population. Front. Pediatr. 6:170 doi: 10.3389/fped.2018.00170

\section{Difficult vs. Severe Asthma: Definition and Limits of Asthma Control in the Pediatric Population}

\author{
Amelia Licari, Ilaria Brambilla, Alessia Marseglia, Maria De Filippo, Valeria Paganelli and \\ Gian L. Marseglia* \\ Department of Pediatric, Fondazione IRCCS Policlinico San Matteo, University of Pavia, Pavia, Italy
}

Evaluating the degree of disease control is pivotal when assessing a patient with asthma. Asthma control is defined as the degree to which manifestations of the disease are reduced or removed by therapy. Two domains of asthma control are identified in the guidelines: symptom control and future risk of poor asthma outcomes, including asthma attacks, accelerated decline in lung function, or treatment-related side effects. Over the past decade, the definition and the tools of asthma control have been substantially implemented so that the majority of children with asthma have their disease well controlled with standard therapies. However, a small subset of asthmatic children still requires maximal therapy to achieve or maintain symptom control and experience considerable morbidity. Childhood uncontrolled asthma is a heterogeneous group and represents a clinical and therapeutic challenge requiring a multidisciplinary systematic assessment. The identification of the factors that may contribute to the gain or loss of control in asthma is essential in differentiating children with difficult-to-treat asthma from those with severe asthma that is resistant to traditional therapies. The aim of this review is to focus on current concept of asthma control, describing monitoring tools currently used to assess asthma control in clinical practice and research, and evaluating comorbidities and modifiable and non-modifiable factors associated with uncontrolled asthma in children, with particular reference to severe asthma.

Keywords: asthma control and severity, severe asthma, difficult to treat asthma, asthma, treatment adherence, severe asthma risk factors

\section{INTRODUCTION}

Asthma is one of the most common chronic diseases affecting all age groups, with up to 20\% of children aged 6-7 years experiencing severe wheezing episodes within a year (1). Childhood asthma is currently defined as a clinical umbrella syndrome encompassing symptoms such as wheezing, shortness of breath, chest tightness, and cough, ranging in severity from mild symptoms to life-threatening attacks (2). In this context, several pathophysiologic components (traits) have been identified in children such as airflow limitation, eosinophilic airway inflammation, airway infection and impaired airway defenses, some of which being treatable (2). The primary goal of asthma management and treatment is to achieve the control of symptoms and underlying airway inflammation, aiming at minimizing the risk of future asthma attacks and medication-related side effects, and preventing the progression of obstructive lung damage during growth and then later in life (3). 
International guidelines emphasize the importance of evaluating asthma control, rather than asthma severity, in order to guide asthma management decisions (3-5). Asthma control is defined as the degree to which manifestations of the disease are reduced or removed by therapy $(6,7)$. Two components of asthma control are identified in the guidelines: symptom control and risk. Symptom control domain refers to daytime symptoms and nighttime symptoms (i.e., cough, wheeze, exercise limitation), reliever use (short-acting $\beta 2$ agonists, SABA) for the treatment of symptoms, and deviation from normal levels of activity (i.e., playing, sleeping, attending work or school), preserving normal or near-normal lung function, and meeting patient and parent expectations. Future risk of poor asthma outcomes domain includes preventing severe asthma attacks (requiring systemic corticosteroids, emergency medical treatment or hospitalization), loss of lung function or impairment of normal lung growth in childhood, and adverse effects caused by medication use (3-7). Asthma severity reflects the intrinsic "activity" of the disease and should be typically assessed both prior to beginning treatment with controller medications, and then at regular intervals to determine degree of responsiveness to treatment. Thus, asthma severity is usually defined from the level of treatment needed to achieve and maintain adequate control (7).

Over the past decade, the definition and the tools of asthma control have been substantially implemented so that the majority of children with asthma have their disease well controlled with standard therapies. However, a small subset of asthmatic children $(<5 \%$ of all pediatric asthma) still requires maximal therapy to achieve or maintain symptom control and experience considerable morbidity (8-11). The identification of the factors that may contribute to the gain or loss of control in asthma is essential in differentiating children with difficult-to-treat asthma from those with severe asthma that is resistant to traditional therapies. The aim of this review is to focus on current concept of asthma control, describing monitoring tools currently used to assess asthma control in clinical practice and research, and evaluating comorbidities and modifiable and non modifiable factors associated with uncontrolled asthma in children, with particular reference to severe asthma.

\section{ASSESSMENT OF ASTHMA CONTROL}

Evaluating asthma control starts with taking a detailed history of frequency of asthma symptoms, sleep disturbances, limitation of activity, and frequency of reliever use in the past 4 weeks. Treatment issues (adherence to therapy and inhaler technique) as well as comorbidities (i.e., nasal disease, eczema, food allergy, obesity, etc.) and factors that may complicate care should be also periodically reviewed (3).

Asthma attacks are characterized by an acute worsening of asthma symptoms in response to a trigger such as allergen exposure, viral infection, environmental irritants (including pollution and cigarette smoke) or a combination of these. Given that asthma attacks can occur also on the background of seemingly good control and normal lung function (12), the concepts of acute asthma attacks and asthma baseline control, although overlapping, are not the same.

\section{Symptom Control}

Common tools for monitoring asthma available in a clinical practice setting can be distinguished in subjective measures, such as asthma diaries and questionnaires-based composites asthma scores, and objective measures, including spirometry, bronchial hyperreactivity tests and biomarkers of airways inflammation (7).

\section{Subjective Measures}

Subjective measures of asthma control include asthma diaries and asthma symptom questionnaires; moreover, visual analog scale (VAS) may be introduced in assessing patient's airways obstruction perception. These tools were initially introduced in clinical research; nevertheless, they are spreading also in clinical practice, since they enable the physicians to strictly monitor their patients' symptoms trends. Each of these tools presents pros and cons, that are briefly reported also in Table $\mathbf{1}$.

Asthma diaries are created to obtain data regarding asthmarelated events on a daily basis. So far asthma diaries validated for clinical practice or for clinical trials are the Pediatric Asthma Diary (PAD) (13), the Pediatric Asthma Caregiver Diary (PACD) (14), the daytime and nocturnal asthma symptom diary scales (15) and the Asthma Control Diary (ACD) (16). Asthma diaries collect data day-to-day, so that they do not depend on patient recall. This feature enables the physician to monitor asthmarelated events in real time and to promptly adjust therapy. The main concern regarding paper diaries is represented by the risk of missing large amounts of data, since this kind of diaries can be retrospectively filled-in by the patient, either with invented data or with false data. In order to solve this problem, the diaries should be administered day-by-day through telematicsprimed device, for instance telephone-administered diaries or online diaries (17-19). This solution has been already adopted in allergic rhinitis (20): as a matter of fact, the MASK-rhinitis study collected symptoms referred by patients, by means of a user-friendly smartphone application; so similar "apps" might be developed in order to be administered to asthmatic patients. Each asthma diary collects a large amount of data for each patient, so another concern about this tool regards the way to evaluate and analyse data derived from asthma diaries in clinical trials. Mixed model analyses should be adopted in order to report the large amount of longitudinal data collected by asthma diaries (21). Furthermore, there is not a standardized method to account for outcome data from asthma diaries: some studies used either "symptom-free days" (22) or "symptom days" (23) so as to obtain information about cost-benefit analysis. Other studies reported the proportion of patients with at least one event or the rate of annual events (24). Both these methods reveal the efficacy of medication in the population level, although a small number of patients may be responsible for a large number of events. Another method to report diaries-derived data is "time to first event" (25), which can estimate the impact of treatment on disease progression.

Asthma symptom questionnaires are intended to monitor asthma-related events over a period between 1 and 4 weeks. 
TABLE 1 | Subjective measures of asthma control.

\begin{tabular}{|c|c|c|}
\hline & Pros & Cons \\
\hline Asthma Diaries & $\begin{array}{l}\text { Do not depend on patient recall } \\
\text { Monitor asthma-related events in real time }\end{array}$ & $\begin{array}{l}\text { They can be retrospectively filled in } \\
\text { Each diary collects large amount of data } \\
\text { Lack of a standardized method to account for outcome data }\end{array}$ \\
\hline \multicolumn{3}{|c|}{ Asthma Symptom Questionnaires } \\
\hline $\begin{array}{l}\text { ACQ, ACT, CACT, } \\
\text { TRACK }\end{array}$ & $\begin{array}{l}\text { Changes in composites asthma scores correlate to clinical } \\
\text { deterioration and to the need of step-up therapy } \\
\text { Provide data easy to analyze }\end{array}$ & $\begin{array}{l}\text { Depend on patient recall } \\
\text { Focus on a small-time window }\end{array}$ \\
\hline CASI & $\begin{array}{l}\text { Identify differences between patients who could seem similar only } \\
\text { on the basis of their clinical symptoms } \\
\text { Useful in clinical research to test impact of additional treatment in } \\
\text { the context of standard care }\end{array}$ & $\begin{array}{l}\text { Need for additional studies to validate the application of this tool } \\
\text { Its role in clinical practice is unclear } \\
\text { It does not include some relevant aspects of disease control }\end{array}$ \\
\hline APGAR & $\begin{array}{l}\text { Provides a wider spectrum of information than other } \\
\text { questionnaires, about features that can be crucial in therapeutic } \\
\text { planning } \\
\text { It is linked to a care algorithm, which can help the physician to } \\
\text { undertake a therapy }\end{array}$ & $\begin{array}{l}\text { Need for additional studies to validate the application of this tool in } \\
\text { clinical practice or in clinical research }\end{array}$ \\
\hline VAS & $\begin{array}{l}\text { Quick and feasible tool for "real-life" monitoring } \\
\text { VAS <6 is a reliable marker of uncontrolled asthma } \\
\text { Provides information about symptom perception }\end{array}$ & $\begin{array}{l}\text { Need for additional studies to validate the application of this tool in } \\
\text { clinical practice or in clinical research }\end{array}$ \\
\hline
\end{tabular}

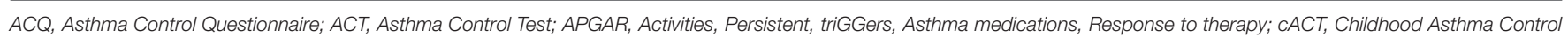
Test; CASI, Composite Asthma Severity Index; TRACK, Test for Respiratory and Asthma Control in Kids; VAS, Visual Analog Scale.

They can be administered only to patients (i.e. Asthma Control Questionnaire-ACQ; Asthma Control Test-ACT), or both to patients and their caregivers (i.e., Childhood Asthma Control Test-ACT), or only to caregivers (i.e., Asthma Therapy Assessment Questionnaire-ATAQ; Test for Respiratory and Asthma Control in Kids-TRACK). Their items usually include the frequency and impact of daytime symptoms, nocturnal symptoms, limitation of normal activities; some questionnaires include also questions about exercise induced-dyspnea (cACT and TRACK) and just one questionnaire evaluate also a measure of lung function (ACQ) (7). From all these data, each questionnaire elaborates a composite score, which express the level of asthma control. Four questionnaires (ACQ, ACT, cACT, TRACK) provide a cut-off value that enables the physician to distinguish between uncontrolled vs. controlled asthma, while ACT and ATAQ have a cut-off value to identify poorly controlled asthma (7). In clinical practice it may be useful to monitor for each patient how the answer to a specific question changes, so as to understand whether the disease is under control or not. Some changes in composites asthma scores correlate to clinical deterioration in asthma control and, consequently, to the need of a step-up of therapy (26). In clinical trials asthma questionnaires are more useful than asthma diaries because their provided data are more easily analyzable than those derived from asthma diaries. As a matter of fact, they have been used to assess the efficacy of different treatments $(27,28)$.

The answers given to asthma questionnaires depend on patient recall. Moreover, the questionnaires focus on a small-time window, which can not entirely reflect the level of disease control, because patients could improve their adherence to therapy just before clinical visit, recent events or recent period of bad control may bias reporting of the whole recall period and the trend of disease attacks can be inconstant through different seasons. In c-ACT, that is administered both to patients and to their caregivers, usually children give lower scores to asthma control than those given by their parents; in addition to that, some studies demonstrated that the correlation between c-ACT score and forced expiratory volume in the first second $\left(\mathrm{FEV}_{1}\right)$ and forced vital capacity (FVC) is stronger in newly diagnosed asthma, while it becomes weaker in patients who undergo treatment for asthma (29).

VAS is a measurement instrument designed as $10 \mathrm{~cm}$-long ruler, on which the patient is asked to put a mark corresponding to his symptom perception, considering that " 0 " represents "severe airflow obstruction perception," while " 10 " represents "no respiratory symptoms." VAS has been already introduced in some allergic conditions (such as rhinitis) as a quick, achievable instrument to monitor in "real-life" setting whether the disease is under control or not (30). Recently VAS has been suggested as a useful tool also for evaluating asthma symptoms perception: there are some evidence that a VAS $<6$ is a reliable marker of uncontrolled asthma in adults (31) and that, in children with bronchial obstruction, poor VAS scores well correlate with respiratory function decrease; moreover, after bronchodilation test, children with initial bronchial obstruction usually report a significant improvement in VAS scores (32). However, the perception of dyspnea has been little studied in severe pediatric asthma (33) and additional studies are needed to validate the application of this tool in clinical research and then in clinical practice.

Composite Asthma Severity Index (CASI) is a subjective measure based on multiple aspects of asthma severity, such as 
impairment, risk and treatment. It accounts for five domains of disease, which include symptoms (day symptoms and night symptoms), controller medication use, lung function tests and asthma attacks. The final score can go from 0 to 20: the higher it is, the more severe the disease is quantified (34). CASI estimates asthma severity by means of the level of medication needed to obtain the present clinical situation, in addition to impairment features and future risk measures. This peculiarity enables the examiner to identify differences between patients who, otherwise, could seem similar only on the basis of their clinical symptoms. Therefore, it is useful for clinical research, since it is sensitive in discriminating among treatment groups even in a well-controlled population, and it can detect the effect of a specific intervention in addition to guidelines-based treatment (35). However, this score needs to be validated on a larger population and its feasibility in clinical practice is unclear. Finally, it does not include some relevant aspects of disease control (i.e. quality of life and economic costs of asthma) (35).

The Asthma APGAR is a newly introduced tool for primary assessment of asthma. The acronym "APGAR" stands for "Activities, Persistent, triGGers, Asthma medications, Response to therapy," it consists in a sequence of questions regarding not only the number of asthma attacks, the presence of diurnal or nocturnal symptoms or the limitation of normal activities due to asthma symptoms, but also the triggers of attacks, the way and the frequency with which the patients take their medicine and whether they think their medicines work or not. Its main distinctive feature is that it gathers a wider spectrum of information than other questionnaires: it mainly focuses on some peculiar aspects of the disease, which are not investigated by means of other questionnaires, but which can be pivotal for tailoring therapy (36). APGAR's questionnaire is also linked to a care algorithm, which is thought to help the physician to undertake a therapy, while all of the other questionnaires so far adopted only give the physician a simple score. Further evidences are needed to validate this tool as a reliable instrument in clinical research and/or in clinical practice.

Beyond electro-monitoring devices, mobile phone-based apps, gadgets and wearable devices, another tool assessing the degree of asthma disease control may be represented by Telemedicine. According to the American Telemedicine Association definition, it consists in "the remote delivery of health care services and clinical information using telecommunications technology" (37). It makes use of internet monitoring, text messages, email reminders. Its efficacy in controlling asthma is still unclear, and it may be cost-effective in rural communities or in underserved areas.

\section{Objective Measures}

No objective gold-standard measure is currently available to diagnose asthma. Among objective measures commonly used to diagnose and monitor asthma, we can identify lung function tests, airway hyperresponsiveness (AHR) tests (Table 2) and biomarkers of airways inflammation.

Lung function tests, particularly spirometry, are objective, noninvasive, and extremely helpful in the diagnosis and followup of patients with asthma. Examination of the FVC, $\mathrm{FEV}_{1}$, and forced expiratory flow rate over $25 \%-75 \%$ of the $\mathrm{FVC}\left(\mathrm{FEF}_{25-75}\right)$ is a reliable way to detect baseline airway obstruction. An obstructive airflow pattern is defined by a reduced $\mathrm{FEV}_{1}(<0.80)$, a reduced $\mathrm{FEV}_{1} / \mathrm{FVC}$ ratio (normally $>0.75$ to 0.80 , and usually $>0.90$ in children) and a concavity of the expiratory flow volume loop during a spirometry test (38). $\mathrm{FEV}_{1} / \mathrm{FVC}$ ratio is the most sensitive tool to assess the airflow obstruction and it is related to asthma severity; as a matter of fact, it can predict asthma-related morbidity and mortality even when $\mathrm{FEV}_{1}$ is still normal (39). However, younger children may have briefer exhalation times and/or lower lung volumes than adults, so that their $\mathrm{FEV}_{1}$ may be comparable to their FVC and, consequently, their $\mathrm{FEV}_{1} / \mathrm{FVC}$ ratio may result normal even in case of airways obstruction (40). $\mathrm{FEF}_{25-75}$ has been proposed as a sensitive indicator of small airway obstruction and a better indicator of a response to bronchodilators and AHR than either $\mathrm{FEV}_{1}$ or FVC; it can be considered normal when it is $\geq 70 \%$ of predicted $\mathrm{FEF}_{25-75}$ (41). Unfortunately, its great variability makes it unreliable as exclusive tool to assess airflow obstruction. In patients affected by asthma, it decreases earlier than other spirometry parameters and is able to predict long-term asthma persistence (42).

TABLE 2 | Obejctive measures of lung function.

\section{Pros}

Spirometry
Objective, noninvasive, helpful for diagnosis and follow-up $\mathrm{FEV}_{1} / \mathrm{FVC}$ ratio can predict asthma-related morbidity and mortality even when $\mathrm{FEV}_{1}$ is still normal

$\mathrm{FEF}_{25-75}$ is a sensitive indicator of small airway obstruction and a better indicator of a response to bronchodilators

\section{Cons}

It relies on patients' ability to carry out the test (unlikely applicable in children younger than 6 years old)

Children may have briefer exhalation times and/or lower lung volumes than adults, consequently, their $\mathrm{FEV}_{1} / \mathrm{FVC}$ ratio may result normal even in case of airways obstruction

Its great variability makes it unreliable as exclusive tool to assess airflow obstruction

The test is extremely effort-dependent

Unlikely applicable in young children

It relies on patients' ability to carry out the test 
Documentation of reversibility of air flow obstruction following inhalation of a bronchodilator is central to the definition of asthma. After bronchodilation, an improvement of at least $12 \%$ and $200 \mathrm{~mL}$ in the $\mathrm{FEV}_{1}$ is considered a positive response and is indicative of reversible air flow obstruction; however, in children, an improvement of $10 \%$ may be adequate to indicate significant improvement. It has been proved that the persistence of a significant degree of bronchodilator responsiveness despite regular treatment according to guidelines may represent a marker of worse asthma control $(43,44)$. Higher bronchodilator reversibility has been added as an additional independent risk factor for asthma attacks in both adults and children in 2018 update of the Global Strategy for Asthma Management and Prevention (3). Besides, reversible or partially reversible airflow obstruction seems to be a distinctive spirometry feature of pediatric severe asthma clinical phenotypes, as demonstrated by the results from severe asthma cohort studies $(45,46)$.

Although spirometry is still considered the gold standard for use in diagnosing and monitoring change in airway function in patients with asthma, other modalities may have particular application in both younger and older children. The Forced Oscillation Technique (FOT) is a lung function modality based on the application of an external oscillatory signal in order to determine the mechanical response of the respiratory system. The method is noninvasive and requires minimal patient cooperation, which makes it suitable for use in young pediatric patients. In the context of asthma, FOT may be more sensitive than spirometry in identifying disturbances of peripheral airways and assessing the level of asthma control or the effectiveness of therapy at the long term (47). Further research is required to determine the exact role of FOT as an objective monitoring tool in pediatric asthma.

Measuring peak of expiratory flow (PEF) may provide some useful information about obstruction in the large central airways. An exaggerated variability in PEF (morning-to-evening more than $20 \%$ ) can confirm the diagnosis of asthma; however, the test is extremely effort-dependent and should not be used alone to diagnose asthma. Variability in PEF was suggested as an indicator of poor asthma control (48); however, studies evaluating the efficacy of PEF monitoring for improving various outcome measures in childhood asthma have yielded conflicting results (49-51).

AHR can be demonstrated either by direct inhaled agents (i.e., methacholine) or by indirect stimulants (i.e., exercise). Provocation tests with direct inhaled agents result positive if they cause a $20 \%$ fall in baseline $\mathrm{FEV}_{1}$, but they are not routinely used in pediatric population (52). Exercise challenge testing consists in assessing the $\mathrm{FEV}_{1}$ variations after $6-8 \mathrm{~min}$ of treadmill exercise; a decrease in $\mathrm{FEV}_{1}$ of more than $10 \%$ is diagnostic of exercise induced bronchoconstriction (53). There is some evidence that exercise-induced bronchoconstriction is more specific than other provocation tests in detecting asthma among pediatric population (54).

Airway inflammation is the hallmark of disease pathophysiology in asthma. Currently bronchoscopy, bronchial biopsy, and bronchoalveolar lavage (BAL) are considered the gold standard to assess airway inflammation and remodeling in asthma; however, the invasiveness of these diagnostic methods limits their use in pediatric age in daily clinical practice. Over the last 10 years, there has been an explosion of interest in the research of non-invasive biomarkers to assess of airway inflammation. Biomarkers for asthma have potential utility for distinguishing the inflammatory and/or molecular pattern or "endotype," predict and monitor responsiveness to specific treatments, and assess of the risk of disease progression (55). Thus, the identification of non-invasive methods to study and monitor disease inflammation represents a relevant challenging field of research in childhood asthma. Most of the current established biomarkers available in clinical practice are related to allergic eosinophilic (Th2-high) inflammation. These include blood or sputum eosinophils, serum IgE, and fractional exhaled nitric oxide (FeNO) (55). Single and combination biomarkers are now being recommended for use in the assessment of children with asthma, in particular with severe asthma, and have been extensively reviewed elsewhere (55). Among these, fractional exhaled NO (FeNO) monitoring has a validated role in current clinical practice as a biomarker useful in asthma diagnosis, monitoring control, and predicting asthma attacks $(56,57)$. Its measurement is simple, safe, and well tolerated, and it has been standardized in school-aged children $(58,59)$. In pediatric asthma, FeNO is now recognized as a surrogate marker of eosinophilic airway inflammation and it is used to identify children with allergic asthma that are likely to respond to ICS treatment (60). Multiple studies have demonstrated that an increased FeNO value at baseline or increasing FeNO values during ICS reduction accurately predict an asthma attack (60). According to the cut-off values published in the American Thoracic Society (ATS) guidelines, a FeNO of $>35$ ppb suggests a likely response to ICS, while a FeNO of $<20 \mathrm{ppb}$ in children indicates a less likely responsiveness to ICS treatment (61). Although FeNO-guided treatment has been associated with significantly fewer asthma attacks and lower attack rate than treatment based on current guidelines in childhood asthma, it not routinely recommended for the general asthma population at present (62). Identifying the populations most likely to benefit from FeNO-guided treatment, as well as establishing the optimal frequency of monitoring FeNO, still require further studies.

\section{Risk Factors for Poor Asthma Outcomes}

The evaluation of symptom control should be always combined with the assessment of risk factors of adverse outcome in children with asthma, both at diagnosis and periodically thereafter.

First of all, having uncontrolled asthma symptoms, experiencing more than 1 episode of asthma attack in last year and/or admission to intensive care unit for asthma are the main independent risk factors for future attacks (63-67); other risk factors that are potentially modified have been recently updated and include: (i) high SABA use (more than 3 canisters/year) (68) and inadequate inhaled corticosteroids (ICS) therapy (not prescribed, poor adherence, incorrect inhaler technique) $(69,70)$; (ii) low $\mathrm{FEV}_{1}$ (even if normal spirometry does not exclude severe asthma in children) $(71,72)$ and higher bronchodilator reversibility (44); (iii) viral infections (rhinovirus and other respiratory viruses), allergen exposure in atopic children, tobacco smoke exposure and outdoor air pollution 
(65). Eosinophilic airway inflammation has been associated with risk of attacks that can be prevented with corticosteroid treatment (2). Blood eosinophils and FeNO have been identified as indirect measures of eosinophilic airway inflammation both in adults and children. These reliable biomarkers may provide a better perspective on risk of attacks and the likely response to treatment with corticosteroids than traditional physiological measures as lung function and asthma symptoms (2). However, blood eosinophilia and elevated FeNO have been recognized as risk factors for acute attacks mainly in adults with allergic asthma taking ICS (3). Overall, it has also been recently established that the presence of any of these mentioned conditions increases the risk of asthma attacks, even if the patient has few asthma symptoms (3).

The severity of asthma attack is a risk marker of both subsequent attacks and mortality from asthma (73). A recent revision of risk factors for severe asthma attacks identified nonwhite race, psycho-social stress and obesity as additional clinical predictors in children (67). Furthermore, cadherinrelated family member 3 (CDHR3) has been identified as a novel susceptibility gene for recurrent severe asthma attacks in children ages 2-6 years: in particular, variants of $\mathrm{CDH} 3$ seem to alter the integrity of airway epithelium and subsequently promote entry and replication of respiratory viruses (74). However, with the exception of history of one recent severe attack, no current clinical or biological markers has been shown to be highly predictive of severe asthma attacks in children (67). Finally, the recent UK National Review of Asthma Deaths (NRAD) identified the conditions at high risk for death from asthma: (i) a single severe attack; (ii) recent discharge from hospital after an acute asthma attack; (iii) use of hospital urgent care facilities in the previous year; (iv) utilization of more than 6 canisters of SABA/year; and (v) failure to attend follow-up appointments ${ }^{1}$. Thus, an asthma attack (even one) should be carefully considered a significant immediate red flag signaling a high risk of future attacks and asthma deaths, in particular in primary care. Moreover, considering that NRAD reported that around $60 \%$ of those who died from asthma were classified as "mild to moderate," the definition of severity by level of treatment should need to be questioned. All these mentioned factors should be added to the conventional definitions of risk as "high risk factors" with the aim to improve care and hopefully reduce the number of deaths.

Early growth characteristics such as pre-term birth, low birth weight and greater infant weight gain have been recently added to the list of risk factors of poor asthma outcomes, all being determinants of airflow limitation and associated with increased risk of childhood asthma $(3,75)$.

Children with uncontrolled asthma, in particular if treated with high-dose ICS and oral corticosteroids (OCS), may experience medication side-effects (i.e. local and systemic sideeffects) $(76,77)$. The risk factors for medication side-effects include frequent use of oral steroids, long-term, high-dose and/or potent ICS use, or concomitant use of P450 inhibitors (such as

${ }^{1}$ Data from National Review of Asthma Deaths' (2014) Available online at: https:// www.rcplondon.ac.uk/projects/outputs/why-asthma-still-kills. ritonavir, ketoconazole, itraconazole) that can markedly increase both bioavailability and decrease clearance of most of the ICS (3). Ongoing monitoring of medication side-effects should be an essential component of a comprehensive childhood asthma management program.

\section{UNCONTROLLED ASTHMA: DIFFICULT VS. SEVERE ASTHMA IN CHILDREN}

The actual asthma management is control-based, including evaluation of symptom control and risk domains; therapeutic strategies are based on a stepwise approach and adjusted in a continuous cycle involving assessment, treatment and review (3). Asthma severity should be determined before the patient is treated, while the assessment of asthma control should be performed after treatment has been instituted; then, both of them should be re-determined at every visit. Step up and step down of treatment should be adapted to every patient in order to maintain asthma control with the minimum dose of medication. The frequency of the assessment of asthma control is variable and depends on disease activity but typically is every 1-6 months. Patients with asthma may be classified into three broad categories as well controlled, partly controlled, or uncontrolled, according to established criteria (Table 3) (3).

Identifying children and adolescents with uncontrolled severe asthma is important because they potentially need close monitoring and additional treatment with advanced biological therapies (78-82). Although accounting for $<5 \%$ of all pediatric asthma (83), uncontrolled severe asthma carries the majority of morbidity and accounts for nearly $50 \%$ of all asthma healthcare costs, and even mortality (8). Children with persistent uncontrolled asthma, despite maximal therapy, are defined as having problematic severe asthma, an umbrella term comprising asthma-mimicking conditions, asthma that is difficult-to-treat because of comorbidities, improper inhaler technique or poor therapeutic adherence, and other environmental factors, and true severe therapy-resistant asthma, as defined by the latest European Respiratory Society/American Thoracic Society (ERS/ATS) definition $(8,84,85)$ : after confirming a diagnosis of asthma

TABLE 3 | Levels of asthma symptom control (to assess retrospectively in the past 4 weeks). adapted from Global Initiative for Asthma (3).

\begin{tabular}{llll}
\hline & Well-controlled & Partly controlled & Uncontrolled \\
\hline $\begin{array}{l}\text { Daytime asthma } \\
\text { symptoms more than }\end{array}$ & None of these & 1 or 2 of these & 3 or 4 of these \\
twice a week & & \\
Night waking due to & \\
asthma & \\
Need for reliever for & \\
symptoms more than & \\
twice a week & \\
Limitation of activity \\
due to asthma
\end{tabular}

${ }^{\star}$ Excluding before exercise. 
and addressing comorbidities, true severe therapy-resistant asthma is that which requires treatment with high dose inhaled glucocorticoids plus a second controller and/or systemic glucocorticoids to prevent asthma from becoming 'uncontrolled' or which remains 'uncontrolled' despite this therapy (8). The identification of the factors that may contribute to the gain or loss of control in asthma is essential in differentiating children with difficult-to-treat asthma from those with severe asthma that is resistant to traditional therapies.

\section{Monitoring and Managing Comorbidities}

Once alternative diagnoses have been excluded and the diagnosis of asthma confirmed, the contribution of comorbid conditions to disease severity should be evaluated. Childhood asthma is associated with several comorbidities (Table 4), variably presenting and depending on the age of the subject (8689). Observations from severe asthma international registries and cohort studies highlighted a distinct picture for pediatric age. In the National Heart, Lung and Blood Institute's Severe Asthma Research Program (SARP) the highest prevalence of comorbid conditions, namely sinus disease, gastroesophageal reflux and obesity, has been found in only $20 \%$ of children studied (clustered as "Group 3") (90). In the Unbiased Biomarkers for the Prediction of Respiratory Disease Outcomes (U-BIOPRED), around $65 \%$ of school-aged children with severe asthma had a diagnosis of concomitant allergic rhinitis, while $40 \%$ of children reported food allergy (91). Unlike upper airway pathology, the relationship between gastroesophageal reflux and asthma is still a matter of debate and there is not enough evidence to support causality; besides, it has been demonstrated that treating reflux does not actually improve asthma outcomes (92). Likewise, the relationship between food allergy and respiratory symptoms is still unclear.

Dysfunctional breathing has been reported as common in some asthma cohort; however, the available data suggest that $5.3 \%$ or more of children with asthma have dysfunctional breathing and that, unlike in adults, it is associated with poorer asthma control (93). Besides, the results of an observational cohort study conducted on 71 children with problematic asthma reported that $15 \%$ of them has dysfunctional breathing, including hyperventilation and vocal cord dysfunction (94). Although it is not possible to draw conclusive estimates on the prevalence of comorbidities in childhood severe asthma, it is well established that the presence of one and/or more comorbid conditions contributes to the loss of asthma control and may complicate the assessment of asthma and potentially impact on its management, outcome and healthcare expenditure $(8,86,88)$. Thus, addressing comorbidities is an essential step in the approach to the child with uncontrolled asthma.

\section{Adherence to Treatment}

Determining if the child is receiving the prescribed controller medication with the adequate inhaler technique is another essential cornerstone of the management of childhood asthma. Poor adherence to treatment is common in asthmatic children, as well as in adults, with reported rates varying from 30 to $70 \%(85,94,95)$ and it should be considered in all children with uncontrolled asthma. Medication issues do not only concern about therapeutic adherence, but also affect management of prescriptions, parental supervision, and use of inhaler devices $(70,94,96)$. These are all potentially modifiable factors that have been associated with loss of asthma control (97). Interventions to improve patient adherence have been tested in several clinical trials and demonstrated a variable efficacy (94). Identifying non-adherent patients and establishing an educational intervention can be complex and time-consuming and require an integrated strategy in everyday clinical practice including regular follow-up assessment at the doctor office, effective patient-centered behavioral interventions, improvement of doctor-patient communication, and new instruments of control such as electronic monitoring (85).

\section{Review of Environmental Factors}

Ongoing exposure to environmental factors is an important cause of poor asthma control in some patients (98). For patients with severe asthma who have an allergic component to their disease, allergen control measures will have an important effect. Potential triggers should be identified during evaluation and need renewed strategies for control. Common inhalant allergens that can contribute to poor asthma control and cause attacks include animal allergens (both pets and pests: cats, dogs, rodents), house dust mites, cockroaches, indoor and outdoor fungi and outdoor plant allergens (tree, grass, ragweed pollen) (99-101). In particular, home and school exposures to pets, house dust mites, mold are associated with severe asthma attacks in children, supporting the importance of atopy in this population (98).

Fungal exposure and sensitization have been recently associated with a sub-phenotype of childhood asthma characterized by increased disease severity, AHR, airway eosinophilic inflammation, more exacerbations and relative

TABLE 4 | Asthma comorbidities in childhood.

\begin{tabular}{ll}
\hline Comorbid Conditions & Potential mechanism contributing to worsen asthma \\
\hline $\begin{array}{l}\text { Obesity } \\
\text { Gastroesophageal reflux }\end{array}$ & $\begin{array}{l}\text { Mechanical effects on lung functions; pro-inflammatory state contributing to airway inflammation; corticosteroid resistance } \\
\text { Direct contamination of the lower airway; esophago-bronchial reflex; reduced efficiency of the lower esophageal sphincter due to }\end{array}$ \\
$\begin{array}{l}\text { Food allergy } \\
\text { Unclear (consider anaphylaxis at rest and on exercise in the differential diagnosis) } \\
\text { Upper Airway Obstruction/Sleep } \\
\text { Disordered Breathing }\end{array} \quad \begin{array}{l}\text { Obesity-associated (common); increased neutrophilic inflammation of the airways } \\
\text { Dysfunctional Breathing }\end{array}$ & Unclear (also consider vocal cord dysfunction and other hyperventilation syndromes in the differential diagnosis)
\end{tabular}


steroid resistance (102). Severe asthma with fungal sensitization (SAFS) is a recognized subphenotype of severe asthma in both children and adults. SAFS is defined as severe, therapyresistant asthma with fungal sensitization demonstrated by a positive skin prick test response or specific $\operatorname{IgE}$ to at least one of 7 fungi (i.e., Aspergillus fumigatus, Alternaria alternata, Cladosporium herbarum, Penicillium chrysogenum, Candida albicans, Trichophyton mentagrophytes, or Botrytis cinerea), with $\operatorname{IgE}<1,000$ and with negative IgG Aspergillus serology (102). Little is known about the mechanisms mediating this subphenotype. Recent evidence suggests a role for innate epithelial cytokine IL-33 in the pathogenesis of SAFS, as higher levels of IL-33 have been found on BAL and airway samples from children with SAFS compared to children without SAFS (102). Till date there are no guidelines for the diagnosis and treatment of SAFS in pediatric population: reduction of environmental fungal exposure in the home and antifungal therapy have been anecdotally successful in some children.

There are also non-allergic factors that potentially contribute to asthma such as exposure to tobacco smoke (including active and passive smoking, as well as vaping), environmental pollution and other irritants (i.e., incense, joss sticks, air fresheners and other aerosol sprays) (103). Tobacco smoke exposure is common in children with asthma and it has been reported in $25 \%$ of cases in a cohort of children having problematic severe asthma (94); it is also associated with loss of asthma control, higher incidence of respiratory infections, increased likehood of asthma attackrelated hospitalizations (104-107); furthermore, it was found that parental (passive) smoking impairs histone deacetylase-2 function, which could contribute to increased corticosteroidresistant inflammation in children with severe asthma (108). In addition, exposure to tobacco smoke exacerbates inflammatory airway responses to allergens (109). Exposures at home, daycare, school and/or work should be reviewed.

\section{Evaluation of Psychosocial Factors}

Asthma attacks may be triggered by both acute and chronic stress, through a supposed effect of enhancement of allergic eosinophilic

\section{REFERENCES}

1. Lai CK, Beasley R, Crane J, Foliaki S, Shah J, Weiland S, et al. Global variation in the prevalence and severity of asthma symptoms: phase three of the International Study of Asthma and Allergies in Childhood (ISAAC). Thorax (2009) 64:476-83. doi: 10.1136/thx.2008.106609

2. Pavord ID, Beasley R, Agusti A, Anderson GP, Bel E, Brusselle G, et al. After asthma: redefining airways diseases. Lancet (2018) 391:350-400. doi: 10.1016/S0140-6736(17)30879-6

3. Global Initiative for Asthma. GINA Guidelines 2018. Global Strategy for Asthma Management and Prevention. (2018) Available online at: http://www. ginasthma.org/

4. National Asthma Education and Prevention Program. Expert Panel Report 3 (EPR-3). Guidelines for the diagnosis and management of asthmasummary report 2007. J Allergy Clin Immunol. (2007) 120:S94-S138. doi: 10.1016/j.jaci.2007.09.043

5. British Thoracic Society. Scottish Intercollegiate Guidelines Network. British Guideline on the Management of Asthma. (2016) Available from https:// airway inflammatory response (110). Among psychosocial issues, anxiety and depression have been more frequently reported in children with persistent and severe asthma rather than mild or intermittent asthma, and in their families $(94,111,112)$. Given the complexity of relationship between these two entities, it is yet to be determined whether anxiety and depression are the cause or result of severe asthma; however, both should be treated on their individual merits.

\section{CONCLUSIONS}

Over the past 10 years, there has been an increasing interest on the concept of asthma control, with development and validation of new and promising "asthma control tools."

Uncontrolled persistent asthma in children represents a clinical challenge and requires a multidisciplinary systematic assessment, including the assessment of comorbid conditions, treatment- related issues, environmental exposures and psychosocial factors. The presence or absence of these factors may contribute to the gain or loss of control and differentiate children with difficult-to-treat asthma from those with true severe therapy-resistant asthma. Finally, the early identification of modifiable factors contributing to childhood uncontrolled asthma is essential to avoid a further and useless escalation of treatment; likewise, addressing a correct diagnosis of true severe therapy-resistant asthma avoids deferring of invasive testing and advanced biological therapies.

\section{AUTHOR CONTRIBUTIONS}

All authors made substantial contribution to the conception of the work, reviewed the literature on the subject, and drafted the final version of the manuscript; AL, VP, and GM revised it critically for important intellectual content. All authors finally approved the version to be published and agreed to be accountable for all aspects of the work in ensuring that questions related to the accuracy or integrity of any part of the work are appropriately investigated and resolved. www.brit-thoracic.org.uk/standards- of-care/guidelines/btssign-britishguideline-on-the-management-of-asthma/

6. Taylor DR, Bateman ED, Boulet LP, Boushey HA, Busse WW, Casale TB, et al. A new perspective on concepts of asthma severity and control. Eur Respir J (2008) 32:545-54. doi: 10.1183/09031936.00155307

7. Dinakar C, Chipps BE. Clinical tools to assess asthma control in children. Pediatrics (2017) 139:e20163438. doi: 10.1542/peds.2016-3438

8. Chung KF, Wenzel SE, Brozek JL, Bush A, Castro M, Sterk PJ, et al. International ERS/ATS guidelines on definition, evaluation and treatment of severe asthma. Eur Respir J. (2014) 43:343-73. doi: 10.1183/09031936.00202013

9. Licari A, Marseglia GL. Current and future challenges in pediatric severe asthma. Curr Med Res Opin (2018) 34:943-44. doi: 10.1080/03007995.2018.1439463

10. Montella S, Baraldi E, Cazzato S, Aralla R, Berardi M, Brunetti LM, et al. Severe asthma features in children: a case-control online survey. Ital J Pediatr. (2016) 42:9. doi: 10.1186/s13052-016$0217-z$ 
11. Licari A, Castagnoli R, Denicolò C, Rossini L, Seminara M, Sacchi $\mathrm{L}$, et al. Omalizumab in children with severe allergic asthma: the italian real-life experience. Curr Respir Med Rev. (2017) 13:36-42. doi: 10.2174/1573398X13666170426094536

12. Reddel HK, Busse WW, Pedersen S, Tan WC, Chen YZ, Jorup C, et al. Should recommendations about starting inhaled corticosteroid treatment for mild asthma be based on symptom frequency: a posthoc efficacy analysis of the START study. Lancet (2017) 389:157-166. doi: 10.1016/S0140-6736(16)31399-X

13. Santanello NC, Davies G, Galant SP, Pedinoff A, Sveum R, Seltzer J, et al. Validation of an asthma symptom diary for interventional studies. Arch Dis Child (1999) 80:414-20.

14. Santanello NC, Demuro-Mercon C, Davies G, Ostrom N, Noonan M, Rooklin A, et al. Validation of a pediatric asthma caregiver diary. J Allergy Clin Immunol. (2000) 106:861-6.

15. Santanello NC, Barber BL, Reiss TF, Friedman BS, Juniper EF, Zhang J. Measurement characteristics of two asthma symptom diary scales for use in clinical trials. Eur Respir J. (1997) 10:646-51.

16. Juniper EF, O’Byrne PM, Ferrie PJ, King DR, Roberts JN. Measuring asthma control. Clinic questionnaire or daily diary? Am J Respir Crit Care Med. (2000) 162:1330-4.

17. Reddel HK, Ware SI, Salome CM, Jenkins CR, Woolcock AJ. Pitfalls in processing home electronic spirometric data in asthma. Eur Respir J. (1998) 12:853-8.

18. Reddel HK, Toelle BG, Marks GB, Ware SI, Jenkins CR, Woolcock AJ. Analysis of adherence to peak flow monitoring when recording of data is electronic. BMJ (2002) 324:146-7. doi: 10.1136/bmj.324.7330.146

19. Koop A, Mösges R. The use of handheld computers in clinical trials. Control Clin Trials (2002) 23:469-80. doi: 10.1016/S0197-2456(02)00224-6

20. Bousquet J, Schunemann HJ, Fonseca J, Samolinski B, Bachert C, Canonica GW, et al. MACVIA-ARIA Sentinel NetworK for allergic rhinitis (MASKrhinitis): the new generation guideline implementation. Allergy (2015) 70:1372-92. doi: 10.1111/all.12686

21. Lambert PC, Burton PR, Abrams KR, Brooke AM. The analysis of peak expiratory flow data using a three-level hierarchical model. Stat Med. (2004) 23:3821-39. doi: 10.1002/sim.1951

22. Tasche MJ, van der Wouden JC, Uijen JH, Ponsioen BP, Bernsen RM, van Suijlekom-Smit LW, et al. Randomised placebo- controlled trial of inhaled sodium cromoglycate in 1-4-year-old children with moderate asthma. Lancet (1997) 350:1060-4.

23. O'Byrne PM, Barnes PJ, Rodriguez-Roisin R, Runnerstrom E, Sandstrom $\mathrm{T}$, Svensson K, et al. Low dose inhaled budesonide and formoterol in mild persistent asthma: the OPTIMA randomized trial. Am J Respir Crit Care Med. (2001) 164:1392-7. doi: 10.1164/ajrccm.164.8.2104102

24. American Lung Association Asthma Clinical Research Centers, Mastronarde JG, Anthonisen NR, Castro M, Holbrook JT, Leone FT, et al. Efficacy of esomeprazole for treatment of poorly controlled asthma. $N$ Engl J Med. (2009) 360:1487-99. doi: 10.1056/NEJMoa0806290

25. Szefler SJ, Baker JW, Uryniak T, Goldman M, Silkoff PE. Comparative study of budesonide inhalation suspension and montelukast in young children with mild persistent asthma. J Allergy Clin Immunol. (2007) 120:1043-50. doi: 10.1016/j.jaci.2007.08.063

26. Chipps BE, Zeiger RS, Dorenbaum A, Borish L, Wenzel SE, Miller DP, et al. Assessment of asthma control and asthma exacerbations in the epidemiology and natural history of asthma: outcomes and treatment regimens (TENOR) observational cohort. Curr Respir Care Rep (2012) 1:259-69. doi: 10.1007/s13665-012-0025-x

27. Arets HG, Kamps AW, Brackel HJ, Mulder PG, Vermue NA, van der Ent CK. Children with mild asthma: do they benefit from inhaled corticosteroids? Eur Respir J (2002) 20:1470-5. doi: 10.1183/09031936.02.00292702

28. Bateman ED, Boushey HA, Bousquet J, Busse WW, Clark TJ, Pauwels RA, et al. Can guideline-defined asthma control be achieved? The gaining optimal asthma control study. Am J Respir Crit Care Med. (2004) 170:836-44. doi: 10.1164/rccm.200401-033OC

29. Piacentini GL, Peroni DG, Bodini A, Bonafiglia E, Rigotti E, Baraldi E, et al. Childhood Asthma Control Test and airway inflammation evaluation in asthmatic children. Allergy (2009) 64:1753-7. doi: 10.1111/j.1398-9995.2009.02068.x
30. Gani F, Lombardi C, Barrocu L, Landi M, Ridolo E, Bugiani M, et al. The control of allergic rhinitis in real life: a multicenter cross-sectional Italian study. Clin Mol Allergy (2018) 16:4. doi: 10.1186/s12948-018-0082-y

31. Ciprandi G, Schiavetti I, Ricciardolo FL. Symptom perception and asthma control. Postgrad Med. (2015) 127:738-43. doi: 10.1080/00325481.2015.1074033

32. Tosca MA, Silvestri M, Rossi GA, Ciprandi G. Perception of bronchodilation assessed by Visual Analogue Scale in children with asthma. Allergol Immunopathol (Madr) (2013) 41:359-63. doi: 10.1016/j.aller.2012.06.002

33. Schweitzer C, Marchal F. Dyspnoea in children. Does development alter the perception of breathlessness? Respir Physiol Neurobiol. (2009) 167:144-53. doi: 10.1016/j.resp.2008.12.001

34. Krouse RZ, Sorkness CA, Wildfire JJ, Calatroni A, Gruchalla R, Hershey $\mathrm{GKK}$, et al. Minimally important differences and risk levels for the Composite Asthma Severity Index. J Allergy Clin Immunol. (2017) 139:105255. doi: 10.1016/j.jaci.2016.08.041

35. Wildfire JJ, Gergen PJ, Sorkness CA, Mitchell HE, Calatroni A, Kattan M, et al. Development and validation of the Composite Asthma Severity Indexan outcome measure for use in children and adolescents. J Allergy Clin Immunol. (2012) 129:694-701. doi: 10.1016/j.jaci.2011.12.962

36. Yawn BP, Wollan PC, Rank MA, Bertram SL, Juhn Y, Pace W. Use of asthma APGAR tools in primary care practices: a cluster-randomized controlled trial. Ann Fam Med. (2018) 16:100-110. doi: 10.1370/afm.2179

37. Data from FAQs. ATA Main [Internet]. (2018) Available online at: https:// www.americantelemed.org/about/telehealth-faqs-

38. Pellegrino R, Viegi G, Brusasco V, Crapo RO, Burgos F, Casaburi R, et al. Interpretative strategies for lung function tests. Eur Respir J. (2005) 26:94868. doi: 10.1183/09031936.05.00035205

39. Mannino DM, Buist AS, Petty TL, Enright PL, Redd SC. Lung function and mortality in the United States: data from the First National Health and Nutrition Examination Survey follow up study. Thorax (2003) 58:388-93. doi: 10.1136/thorax.58.5.388

40. Raywood E, Lum S, Aurora P, Pike K. The bronchodilator response in preschool children: a systematic review. Pediatr Pulmonol. (2016) 51:124250. doi: 10.1002/ppul.23459

41. Marseglia GL, Cirillo I, Vizzaccaro A, Klersy C, Tosca MA, La Rosa M, et al. Role of forced expiratory flow at $25-75 \%$ as an early marker of small airways impairment in subjects with allergic rhinitis. Allergy Asthma Proc. (2007) 28:74-8.

42. Siroux V, Boudier A, Dolgopoloff M, Chanoine S, Bousquet J, Gormand $\mathrm{F}$, et al. Forced midexpiratory flow between $25 \%$ and $75 \%$ of forced vital capacity is associated with long-term persistence of asthma and poor asthma outcomes. J Allergy Clin Immunol. (2016) 137:1709-16.e6. doi: 10.1016/j.jaci.2015.10.029

43. Galant SP, Morphew T, Newcomb RL, Hioe K, Guijon O, Liao O. The relationship of the bronchodilator response phenotype to poor asthma control in children with normal spirometry. J Pediatr. (2011) 158:953-9.e1. doi: 10.1016/j.jpeds.2010.11.029

44. Pongracic JA, Krouse RZ, Babineau DC, Zoratti EM, Cohen RT, Wood RA, et al. Distinguishing characteristics of difficult-to-control asthma in innercity children and adolescents. J Allergy Clin Immunol. (2016) 138:1030-41. doi: 10.1016/j.jaci.2016.06.059

45. Sorkness RL, Teague WG, Penugonda M, Fitzpatrick AM, National Institutes of Health, National Heart, Lung, and Blood Institute's Severe Asthma Research Program. Sex dependence of airflow limitation and air trapping in children with severe asthma. J Allergy Clin Immunol. (2011) 127:1073-4. doi: 10.1016/j.jaci.2010.12.1079

46. Fitzpatrick AM, Moore WC. Severe asthma phenotypes-how should they guide evaluation and treatment? J Allergy Clin Immunol Pract. (2017) 5:9018. doi: 10.1016/j.jaip.2017.05.015

47. Skylogianni E, Douros K, Anthracopoulos MB, Fouzas S. The forced oscillation technique in paediatric respiratory practice. Paediatr Respir Rev. (2016) 18:46-51. doi: 10.1016/j.prrv.2015. 11.001

48. Kaminsky DA, Wang LL, Bates JH, Thamrin C, Shade DM, Dixon AE, et al. Fluctuation analysis of peak expiratory flow and its association with treatment failure in asthma. Am J Respir Crit Care Med. (2017) 195:993-9. doi: 10.1164/rccm.201601-0076OC 
49. Goldberg S, Springer C, Avital A, Godfrey S, Bar-Yishay E. Can peak expiratory flow measurements estimate small airway function in asthmatic children? Chest (2001) 120:482-8. doi: 10.1378/chest.120.2.482

50. Yoos HL, Kitzman H, McMullen A, Henderson C, Sidora K. Symptom monitoring in childhood asthma: a randomized clinical trial comparing peak expiratory flow rate with symptom monitoring. Ann Allergy Asthma Immunol. (2002) 88:283-91. doi: 10.1016/S1081-1206(10)62010-8

51. Wensley D, Silverman M. Peak flow monitoring for guided self-management in childhood asthma: a randomized controlled trial. Am J Respir Crit Care Med. (2004) 170:606-12. doi: 10.1164/rccm.200307-1025OC

52. Park GM, Han HW, Kim JY, Lee E, Cho HJ, Yoon J, et al. Association of symptom control with changes in lung function, bronchial hyperresponsiveness, and exhaled nitric oxide after inhaled corticosteroid treatment in children with asthma. Allergol Int (2016) 65:439-443. doi: 10.1016/j.alit.2016.03.011

53. Crapo RO, Casaburi R, Coates AL, Enright PL, Hankinson JL, Irvin CG, et al. Guidelines for methacholine and exercise challenge testing-1999. This official statement of the American Thoracic Society was adopted by the ATS Board of Directors, July 1999. Am J Respir Crit Care Med. (2000) 161:309-29. doi: 10.1164/ajrccm.161.1.ats11-99

54. Carlsen KH, Engh G, Mørk M, Schrøder E. Cold air inhalation and exerciseinduced bronchoconstriction in relationship to metacholine bronchial responsiveness: different patterns in asthmatic children and children with other chronic lung diseases. Respir Med. (1998) 92:308-15.

55. Licari A, Castagnoli R, Brambilla I, Marseglia A, Tosca MA, Marseglia GL, et al. Asthma endotyping and biomarkers in childhood asthma. Pediatr Allergy Immunol Pulmonol. (2018) 31:1-12. doi: 10.1089/ped.2018.0886

56. Pijnenburg MW, De Jongste JC. Exhaled nitric oxide in childhood asthma: a review. Clin Exp Allergy (2008) 38:246-59. doi: 10.1111/j.1365-2222.2007.02897.x

57. Gomersal T, Harnan S, Essat M, Tappenden P, Wong R, Lawson R, et al. A systematic review of fractional exhaled nitric oxide in the routine management of childhood asthma. Pediatr Pulmonol (2016) 51:316-28. doi: 10.1002/ppul.23371

58. Baraldi E, de Jongste JC, European Respiratory Society/American Thoracic Society (ERS/ATS) Task Force. Measurement of exhaled nitric oxide in children, 2001. Eur Respir J. (2002) 20:223-237. doi: 10.1183/09031936.02.00293102

59. Horváth I, Barnes PJ, Loukides S, Sterk PJ, Högman M, Olin AC, et al. A European Respiratory Society technical standard: exhaled biomarkers in lung disease. Eur Respir J (2017) 49:1600965. doi: 10.1183/13993003.009 65-2016

60. Spahn JD, Malka J, Szefler SJ. Current application of exhaled nitric oxide in clinical practice. J Allergy Clin Immunol. (2016) 138:1296-8. doi: 10.1016/j.jaci.2016.09.002

61. Dweik RA, Boggs PB, Erzurum SC, Irvin CG, Leigh MW, Lundberg JO, et al. An official ATS clinical practice guideline: interpretation of exhaled nitric oxide levels (FENO) for clinical applications. Am J Respir Crit Care Med. (2011) 184:602-15. doi: 10.1164/rccm.9120-11ST

62. Petsky HL, Kew KM, Chang AB. Exhaled nitric oxide levels to guide treatment for children with asthma. Cochrane Database Syst Rev. (2016) 11:CD011439. doi: 10.1002/14651858.CD011439.pub2

63. Turner MO, Noertjojo K, Vedal S, Bai T, Crump S, Fitzgerald JM. Risk factors for near-fatal asthma. A case-control study in hospitalized patients with asthma. Am J Respir Crit Care Med. (1998) 157:1804-9. doi: 10.1164/ajrccm.157.6.9708092

64. Haselkorn T, Fish JE, Zeiger RS, Szefler SJ, Miller DP, Chipps BE, et al. Consistently very poorly controlled asthma, as defined by the impairment domain of the Expert Panel Report 3 guidelines, increases risk for future severe asthma exacerbations in The Epidemiology and Natural History of Asthma: outcomes and Treatment Regimens (TENOR) study. J Allergy Clin Immunol. (2009) 124:895-902.e1-4. doi: 10.1016/j.jaci.2009. 07.035

65. Forno E, Celedón JC. Predicting asthma exacerbations in children. Curr Opin Pulm Med. (2012) 18:63-9. doi: 10.1097/MCP.0b013e32834db288

66. Carroll CL, Uygungil B, Zucker AR, Schramm CM. Identifying an at-risk population of children with recurrent near-fatal asthma exacerbations. $J$ Asthma (2010) 47:460-4. doi: 10.3109/02770903.2010.481344
67. Puranik S, Forno E, Bush A, Celedón JC. Predicting severe asthma exacerbations in children. Am J Respir Crit Care Med. (2017) 195:854-9. doi: 10.1164/rccm.201606-1213PP

68. Patel M, Pilcher J, Reddel HK, Pritchard A, Corin A, Helm C, et al. Metrics of salbutamol use as predictors of future adverse outcomes in asthma. Clin Exp Allergy (2013) 43:1144-51. doi: 10.1111/cea.12166

69. Ernst P, Spitzer WO, Suissa S, Cockcroft D, Habbick B, Horwitz RI, et al. Risk of fatal and near-fatal asthma in relation to inhaled corticosteroid use. JAMA (1992) 268:3462-4

70. Melani AS, Bonavia M, Cilenti V, Cinti C, Lodi M, Martucci P, et al. Inhaler mishandling remains common in real life and is associated with reduced disease control. Respir Med (2011) 105:930-8. doi: 10.1016/j.rmed.2011.01.005

71. Fuhlbrigge AL, Kitch BT, Paltiel AD, Kuntz KM, Neumann PJ, Dockery DW, et al. FEV1 is associated with risk of asthma attacks in a pediatric population. J Allergy Clin Immunol. (2001) 107:61-7. doi: 10.1067/mai.2001.111590

72. Bossley CJ, Fleming L, Ullmann N, Gupta A, Adams A, Nagakumar P, et al. Assessment of corticosteroid response in pediatric patients with severe asthma by using a multidomain approach. J Allergy Clin Immunol. (2016) 138:413-420.e6. doi: 10.1016/j.jaci.2015.12.1347

73. Levy ML, Winter R. Asthma deaths: what now? Thorax (2015) 70:209-210. doi: 10.1136/thoraxjnl-2015-206800

74. Bønnelykke K, Sleiman P, Nielsen K, Kreiner-Møller E, Mercader JM, Belgrave D, et al. A genome-wide association study identifies CDHR3 as a susceptibility locus for early childhood asthma with severe exacerbations. Nat Genet (2014) 46:51-5. doi: 10.1038/ng.2830

75. den Dekker HT, Sonnenschein-van der Voort AMM, de Jongste JC, AnessiMaesano I, Arshad SH, Barros H, et al. Early growth characteristics and the risk of reduced lung function and asthma: a meta-analysis of 25,000 children. J Allergy Clin Immunol. (2016) 137:1026-35. doi: 10.1016/j.jaci.2015. 08.050

76. Kaur S, Singh V. Asthma and medicines-long-term side-effects, monitoring and dose titration. Indian J Pediatr. (2018). doi: 10.1007/s12098-017-2553-4. [Epub ahead of print].

77. Raissy HH, Kelly HW. Benefits and risks of long-term asthma management in children: where are we heading? Drug Saf. (2017) 40:201-10. doi: 10.1007/s40264-016-0483-0

78. Licari A, Marseglia A, Caimmi S, Castagnoli R, Foiadelli T, Barberi $\mathrm{S}$, et al. Omalizumab in children. Paediatr Drugs (2014) 16:491-502. doi: 10.1007/s40272-014-0107-z

79. Licari A, Marseglia G, Castagnoli R, Marseglia A, Ciprandi G. The discovery and development of omalizumab for the treatment of asthma. Expert Opin Drug Discov. (2015) 10:1033-42. doi: 10.1517/17460441.2015.1048220

80. Ciprandi G, Marseglia GL, Castagnoli R, Valsecchi C, Tagliacarne C, Caimmi S, et al. From IgE to clinical trials of allergic rhinitis. Expert Rev Clin Immunol. (2015) 11:1321-33. doi: 10.1586/1744666X.2015.10 86645

81. Licari A, Castagnoli R, Panfili E, Marseglia A, Brambilla I, Marseglia GL. An update on anti-ige therapy in pediatric respiratory diseases. Curr Respir Med Rev. (2017) 13:22-9. doi: 10.2174/1573398X13666170616110738

82. Licari A, Castagnoli R, Brambilla I, Marseglia A, Tosca MA, Marseglia GL, et al. New approaches for identifying and testing potential new anti-asthma agents. Expert Opin Drug Discov. (2018) 13:51-63. doi: 10.1080/17460441.2018.1396315

83. Lang A, Carlsen KH, Haaland G, Devulapalli CS, Munthe-Kaas M, Mowinckel P, et al. Severe asthma in childhood: assessed in 10 year olds in a birth cohort study. Allergy (2008) 63:1054-60. doi: 10.1111/j.1398-9995.2008.01672.x

84. Bush A, Fleming L, Saglani S. Severe asthma in children. Respirology (2017) 22:886-97. doi: 10.1111/resp.13085

85. Ramratnam SK, Bacharier LB, Guilbert TW. Severe asthma in children. J Allergy Clin Immunol Pract. (2017) 5:889-98. doi: 10.1016/j.jaip.2017.04.031

86. de Groot EP, Duiverman EJ, Brand PL. Comorbidities of asthma during childhood: possibly important, yet poorly studied. Eur Respir J. (2010) 36:671-8. doi: 10.1183/09031936.00185709

87. Licari A, Castagnoli R, Denicolò CF, Rossini L, Marseglia A, Marseglia GL. The nose and the lung: united airway disease? Front Pediatr. (2017) 5:44. doi: $10.3389 /$ fped.2017.00044 
88. Licari A, Brambilla I, De Filippo M, Poddighe D, Castagnoli R, Marseglia GL. The role of upper airway pathology as a comorbidity in severe asthma. Expert Rev Respir Med. (2017) 11:855-65. doi: 10.1080/17476348.2017.1381564

89. Peters U, Dixon AE, Forno E. Obesity and asthma. J Allergy Clin Immunol. (2018) 141:1169-79. doi: 10.1016/j.jaci.2018.02.004

90. Fitzpatrick AM, Teague WG, Meyers DA, Peters SP, Li X, Li H, et al. Heterogeneity of severe asthma in childhood: confirmation by cluster analysis of children in the National Institutes of Health/National Heart, Lung, and Blood Institute Severe Asthma Research Program. J Allergy Clin Immunol. (2011) 127:382-389.e1-13. doi: 10.1016/j.jaci.2010.11.015

91. Fleming L, Murray C, Bansal AT, Hashimoto S, Bisgaard H, Bush A, et al. The burden of severe asthma in childhood and adolescence: results from the paediatric U-BIOPRED cohorts. Eur Respir J. (2015) 46:1322-33. doi: 10.1183/13993003.00780-2015

92. Writing Committee for the American Lung Association Asthma Clinical Research Centers, Holbrook JT, Wise RA, Gold BD, Blake K, Brown ED, et al. Lansoprazole for children with poorly controlled asthma: a randomized controlled trial. JAMA (2012) 307:373-81. doi: 10.1001/jama.2011.2035

93. Barker NJ, Jones M, O’Connell NE, Everard ML. Breathing exercises for dysfunctional breathing/hyperventilation syndrome in children. Cochrane Database Syst Rev. (2013) 12:CD010376. doi: 10.1002/14651858.CD010376.pub2

94. Bracken M, Fleming L, Hall P, Van Stiphout N, Bossley C, Biggart $\mathrm{E}$, et al. The importance of nurse-led home visits in the assessment of children with problematic asthma. Arch Dis Child (2009) 94:780-4. doi: 10.1136/adc.2008.152140

95. Chan AHY, Stewart AW, Foster JM, Mitchell EA, Camargo CA Jr, Harrison J. Factors associated with medication adherence in schoolaged children with asthma. ERJ Open Res. (2016) 2:00087-2015. doi: 10.1183/23120541.00087-2015

96. Levy ML, Hardwell A, McKnight E, Holmes J. Asthma patients' inability to use a pressurised metered-dose inhaler (pMDI) correctly correlates with poor asthma control as defined by the Global Initiative for Asthma (GINA) strategy: a retrospective analysis. Prim Care Respir J. (2013) 22: 406-11. doi: 10.4104/pcrj.2013.00084

97. Klok T, Kaptein AA, Duiverman EJ, Brand PL. Long-term adherence to inhaled corticosteroids in children with asthma: observational study. Respir Med. (2015) 109:1114-9. doi: 10.1016/j.rmed.2015.07.016

98. Sala KA, Carroll CL, Tang YS, Aglio T, Dressler AM, Schramm CM. Factors associated with the development of severe asthma exacerbations in children. J Asthma (2011) 48:558-64. doi: 10.3109/02770903.2011.585411

99. Platts-Mills TA, Carter MC. Asthma and indoor exposure to allergens. N Engl J Med (1997) 336:1382. doi: 10.1056/NEJM199705083361909

100. Pongracic JA, O’Connor GT, Muilenberg ML, Vaughn B, Gold DR, Kattan M, et al. Differential effects of outdoor versus indoor fungal spores on asthma morbidity in inner-city children. J Allergy Clin Immunol (2010) 125:593. doi: 10.1016/j.jaci.2009.10.036

101. Darrow LA, Hess J, Rogers CA, Tolbert PE, Klein M, Sarnat SE. Ambient pollen concentrations and emergency department visits for asthma and wheeze. J Allergy Clin Immunol. (2012) 130:630-38.e4. doi: 10.1016/j.jaci.2012.06.020

102. Castanhinha S, Sherburn R, Walker S, Gupta A, Bossley CJ, Buckley $\mathrm{J}$, et al. Pediatric severe asthma with fungal sensitization is mediated by steroid-resistant IL-33. J Allergy Clin Immunol. (2015) 136:312-22.e7. doi: 10.1016/j.jaci.2015.01.016

103. Rottier BL, Eber E, Hedlin G, Turner S, Wooler E, Mantzourani E, et al. Monitoring asthma in childhood: management-related issues. Eur Respir Rev. (2015) 24:194-203. doi: 10.1183/16000617.00003814

104. Kit BK, Simon AE, Brody DJ, Akinbami LJ. US prevalence and trends in tobacco smoke exposure among children and adolescents with asthma. Pediatrics (2013) 131:407-14. doi: 10.1542/peds.2012-2328

105. Akinbami LJ, Kit BK, Simon AE. Impact of environmental tobacco smoke on children with asthma, United States, 2003-2010. Acad Pediatr. (2013) 13:508-16. doi: 10.1016/j.acap.2013.07.003

106. Howrylak JA, Spanier AJ, Huang B, Peake RW, Kellogg MD, Sauers H, et al. Cotinine in children admitted for asthma and readmission. Pediatrics (2014) 133:e355-62. doi: 10.1542/peds.2013-2422

107. Lang JE, Dozor AJ, Holbrook JT, Mougey E, Krishnan S, Sweeten S, et al. Biologic mechanisms of environmental tobacco smoke in children with poorly controlled asthma: results from a multicenter clinical trial. J Allergy Clin Immunol Pract. (2013) 1:172-80. doi: 10.1016/j.jaip.2012.11.006

108. Kobayashi Y, Bossley C, Gupta A, Akashi K, Tsartsali L, Mercado N, et al. Passive smoking impairs histone deacetylase-2 in children with severe asthma. Chest (2014) 145:305-12. doi: 10.1378/chest.13-0835

109. Diaz-Sanchez D, Rumold R, Gong H Jr. Challenge with environmental tobacco smoke exacerbates allergic airway disease in human beings. J Allergy Clin Immunol. (2006) 118:441-6. doi: 10.1016/j.jaci.2006.04.047.

110. Liu LY, Coe CL, Swenson CA, Kelly EA, Kita H, Busse WW. School examinations enhance airway inflammation to antigen challenge. Am J Respir Crit Care Med. (2002) 165:1062-7. doi: 10.1164/ajrccm.165.8.2109065

111. Kohlboeck G, Koletzko S, Bauer C-P, von Berg A, Berdel D, Krämer $\mathrm{U}$, et al. Association of atopic and non-atopic asthma with emotional symptoms in school children. Pediatr Allergy Immunol. (2013) 24:230-6. doi: $10.1111 /$ pai.12056

112. Goodwin RD, Fergusson DM, Horwood LJ. Asthma and depressive and anxiety disorders among young persons in the community. Psychol Med. (2004) 34:1465-74.

Conflict of Interest Statement: The authors declare that the research was conducted in the absence of any commercial or financial relationships that could be construed as a potential conflict of interest.

Copyright (C) 2018 Licari, Brambilla, Marseglia, De Filippo, Paganelli and Marseglia. This is an open-access article distributed under the terms of the Creative Commons Attribution License (CC BY). The use, distribution or reproduction in other forums is permitted, provided the original author(s) and the copyright owner are credited and that the original publication in this journal is cited, in accordance with accepted academic practice. No use, distribution or reproduction is permitted which does not comply with these terms. 